\title{
A model for simultaneous encoding of "where" and "what" information in prefrontal cortex Efrat Barak-Shimron*1, Ron Meir ${ }^{2}$ and Yehoshua Y Zeevi ${ }^{2}$
}

\author{
Address: ${ }^{1}$ Department of Medicine, Technion - Israel Institute of Technology, Haifa, 32000, Israel and ${ }^{2}$ Department of Electrical Engineering, \\ Technion - Israel Institute of Technology, Haifa, 32000, Israel \\ Email: Efrat Barak-Shimron* - efratbarak@hotmail.com \\ * Corresponding author
}

from Eighteenth Annual Computational Neuroscience Meeting: CNS*2009

Berlin, Germany. 18-23 July 2009

Published: 13 July 2009

BMC Neuroscience 2009, I0(Suppl I):P283 doi:I0.II86/I47|-2202-I0-SI-P283

This abstract is available from: http://www.biomedcentral.com//47I-2202/I0/SI/P283

(C) 2009 Barak-Shimron et al; licensee BioMed Central Ltd.

\section{Introduction}

In contrast to the classical theory of segregated cortical representation of information regarding the identity ("what") and location ("where") of a visual object, recent experimental results indicate that neurons in the primate prefrontal cortex convey combined information about both [1]. Moreover, this information was found to be maintained after stimulus removal, suggesting that these neurons contribute to working memory. To date, the mechanisms that underlie this integrated representation are unknown. In this study, we propose a model of a cortical network with biologically realistic properties that demonstrates a combined representation of stimulus identity and location.

\section{Methods}

The network is comprised of neurons embedded in a twodimensional surface and involves two types of connections. The first, memory-related connections, have weights that are modified using Hebbian learning to store a set of memory patterns in the network. Based on experimental evidence related to the locality and sparseness of cortical connectivity [2], the probability of creating these connections is assumed to be a narrow Gaussian function of distance. Secondly, lateral inhibition is implemented through a Mexican hat type of interaction [3]; accordingly, each neuron projects inhibitory synapses on neurons that are located on a ring that is close, but not adjacent, to it.

\section{Results}

When the network is given a localized cue in the form of a short-time injected current, the attractor dynamics of the memory-related connections drive it to a state that retrieves the cued pattern, which codes the stimulus identity. At the same time, the lateral inhibition mechanism restricts the activity to a small area around the stimulated location, so the network exhibits an activity "bump" that codes the stimulus location [4]. Notably, our model behavior points to the existence of a tradeoff between the accuracy of the two types of information. When the radius of the lateral inhibition ring is small, high localization is achieved but the pattern retrieval is degraded. In contrast, when this radius is increased, the retrieval is improved but the activity spreads, so the "where" information is diminished.

Interestingly, we also find that the combined representation of stimulus identity and position can be obtained in networks with small world topology, in which a small fraction of the memory-related local connections is replaced by random, long-term connections [5]. This connectivity scheme, which was observed experimentally in brain networks [6], is considered more realistic than the fully local one. Furthermore, results of large-scale simulations indicate that the integrated representation is robust with regard to the signal-to-noise ratio of the cue. 


\section{Discussion}

In our model, the combination of associative memory and lateral inhibition mechanisms enables the network to exhibit an activity profile that reflects both the "where" and "what" properties of a visual stimulus. The interplay between these mechanisms results in a tradeoff between the conveyed information qualities. Such tradeoffs are common in biological systems, and they reflect a constraint imposed by the universal principle of uncertainty.

\section{References}

I. Rao SC, Rainer G, Miller EK: Integration of what and where in the primate perforntal cortex. Science 1997, 276:82I-824.

2. Hellwig B: $\mathbf{A}$ quantitative analysis of the local connectivity between pyramidal neurons in layers $2 / 3$ of the rat visual cortex. Biological Cybernetics 2000, 82:III-I2I.

3. Amari S: Neural theory of association and concept-formation. Biological Cybernetics 1977, 26: 175-185.

4. Wang XJ: Synaptic reverberation underlying mnemonic persistent activity. Trends in Neuroscience 200I, 24:455-463.

5. Watts DJ, Strogatz SH: Collective dynamics of networks. Nature 1998, 393:440-442.

6. Stam CJ, Reijneveld JC: Graph theoretical analysis of complex networks in the brain. Nonlinear Biomedical Physics 2007, I:3.

Publish with Bio Med Central and every scientist can read your work free of charge

"BioMed Central will be the most significant development for disseminating the results of biomedical research in our lifetime."

Sir Paul Nurse, Cancer Research UK

Your research papers will be:

- available free of charge to the entire biomedical community

- peer reviewed and published immediately upon acceptance

- cited in PubMed and archived on PubMed Central

- yours - you keep the copyright 